\title{
Antimicrobial capacity of Aloe vera and propolis dentifrice against Streptococcus mutans strains in toothbrushes: an in vitro study
}

\author{
Patrícia Fernanda Roesler BERTOLINI', Oswaldo BIONDI FILHO², Arnaldo POMILIO³ , Sérgio Luiz PINHEIRO4 \\ Silva de CARVALHO
}

\author{
1- DDS, MSc, PhD, Professor, Department of Periodontics, Paulista University, Campinas and Sorocaba; Associate Professor, Department of Clinical Dentistry, \\ Pontifical Catholic University, Campinas, SP, Brazil. \\ 2- DDS, MSc, Assistant Professor, Department of Periodontics, Paulista University, Campinas and Sorocaba, SP, Brazil. \\ 3- DDS, MSc, PhD, Associate Professor, Department of Clinical Dentistry, Pontifical Catholic University, Campinas, SP, Brazil. \\ 4- DDS, MSc, PhD, Full Professor, Department of Clinical Dentistry, Pontifical Catholic University, Campinas, SP, Brazil. \\ 5- Graduate student, Department of Clinical Dentistry, Pontifical Catholic University, Campinas, SP, Brazil.
}

Corresponding address: Profa. Dra. Patrícia Fernanda Roesler Bertolini - Rua América, 615 - apto 83 - Araras - SP - 13.600-100 - Phone: (19) 9644-5582 - e-mail: bertolinipfr@hotmail.com

Received: November 01, 2009 - Modification: May 13, 2010 - Accepted: May 30, 2010

\section{ABSTRACT}

\begin{abstract}
O bjectives: This study evaluated in vitro the efficiency of Aloe vera and propolis dentifrice on reducing the contamination of toothbrush bristles by a standard strain of Streptococcus mutans (ATCC 25175; SM), after toothbrushing. Material and Methods: Fifteen sterile toothbrushes were randomly divided into 5 toothbrushing groups: I (negative control): without dentifrice; II: with fluoridated dentifrice; III: with triclosan and gantrez dentifrice; IV (positive control): without dentifrice and irrigation with $10 \mathrm{~mL}$ of $0.12 \%$ chlorhexidine gluconate; $\mathrm{V}$ : with Aloe vera and propolis dentifrice. In each group, 1 sterile bovine tooth was brushed for $1 \mathrm{~min}$, where the toothbrush bristles were contaminated with $25 \mu \mathrm{L}$ of SM. After toothbrushing, the bristles were stored in individual test tubes with 3 $\mathrm{mL}$ of $\mathrm{BHI}$ under anaerobiosis of $37^{\circ} \mathrm{C}$ for $48 \mathrm{~h}$. Then, they were seeded with sterile swab in triplicate in the Mitis salivarius - Bacitracin culture medium. The samples were kept under anaerobiosis of $37^{\circ} \mathrm{C}$ for $48 \mathrm{~h}$. Scores were used to count the number of colony forming units (cfu). The results were submitted to the Mann-Whitney statistical test at $5 \%$ significance level. Results: There was statistically significant difference $(p<0.05)$ for the reduction of bristle contamination comparing groups II, III, IV and V to group I. Conclusions: It may be stated that after toothbrushing, the Aloe vera and propolis dentifrice reduced the contamination of toothbrush bristles by SM, without differentiation from the other chemical agents used.
\end{abstract}

Key words: Dentifrices. Toothbrushing. Streptococcus mutans.

\section{INTRODUCTION}

Since the 1920's, there have been reports in the literature which demonstrate the preoccupation about the toothbrush contamination by microorganisms associated with mouth infections ${ }^{6}$, as well as their transmission ${ }^{18,19}$ through their bristles, acting as vehicle for the bacterial reintroduction in the oral cavity.

Sato, et al. ${ }^{23}$ (2004) evaluated the survival of microorganisms in toothbrushes, after their use for 1 week. The results showed the presence of feasible bacteria in their bristles, with several kinds of forms, from the beginning to the end of the experimental period, with prevalence of grampositive cocci for gram-negative bacilli, respectively. Streptococcus from the mutans group has been frequently associated with the contamination of toothbrush bristles ${ }^{20}$.

During oral hygiene, the use of dentifrice has been indicated not only as a cosmetic tool associated with flavor, but also a therapeutic agent to treat oral diseases, caries and periodontal disease, for having certain chemical agents ${ }^{1}$. Some 
authors ${ }^{10,25}$ have investigated the likelihood of some chemical agents present in the dentifrices acting on the reduction of viable microorganisms that contaminate the toothbrush bristles after their use.

Triclosan is an antimicrobial agent used in dentifrices, which has some characteristics such as having a broad-spectrum of antimicrobial activity, being non-ionic and, when associated with zinc citrate or to gantrez, showing anti-plaque and antiinflammatory effects when used for periods longer than 6 months ${ }^{12}$.

Considering its effective, nontoxic, costeffective and easily applicable characteristic, solutions based on triclosan-containing dentifrice have been tested for the disinfection of toothbrushes contaminated in vitro by standardized suspensions of S. pyogenes, Staphylococcus aureus or Candida albicans ${ }^{13}$.

Efstratiou, et al. ${ }^{8}$ (2007) observed that 24 $\mathrm{h}$ after the use of the toothbrushes, there was contamination of their bristles by cariogenic and periodontopathogenic microorganisms. The results showed that oral hygiene performed by the association of toothbrush with a dentifrice containing triclosan reduced significantly the residual contamination of the bristles.

Propolis is a natural resinous substance, which results from the collection that Apis mellifera bees made from leaves, flowers and certain barks ${ }^{7}$. Among its biological activities ${ }^{11}$, its antimicrobial activity is outstanding and varies according to its flavonoid contents, which depend on the vegetation of the collection area ${ }^{7,14}$.

Aloe vera is a plant of the liliaceous family, popularly known as "babosa". Its mucilaginous gel is obtained from its leaves and has been largely studied in the healthcare area due to its antiinflammatory and antimicrobial properties ${ }^{16,22}$. According to Barreto, et al. ${ }^{1}$ (2005), Aloe vera abounds with aloeferon, which acts on the tissue healing. It contains acemannan, which is a mucopolysaccharide with antiviral, antifungal and antimicrobial action, for activating the immune system and stimulating the antibody production; it also contains anthraquinone, which is an antiseptic substance.

Propolis associated with Aloe vera has caused great interest in Dentistry due their action against pathogenic microorganisms and inflammatory properties $^{1}$. Therefore, the goal of this study was to evaluate in vitro the antimicrobial capacity of the dentifrice containing Aloe vera and propolis on the contamination reduction of toothbrush bristles by Streptococcus mutans standard strain.

\section{MATERIAL AND METHODS}

Fifteen toothbrushes were purchased (Sanifill
Leader Vip, Facilit Odontológica e Perfumaria Ltda, Curitiba, PR, Brazil) with the following characteristics: small head, soft nylon bristles, with the same height, rounded tips, with 30 tufts. The handle of each toothbrush was cut $3 \mathrm{~cm}$ far from the tip end to help placing the dentifrice onto the bristles. The toothbrushes and their handles were individually packed for sterilization in autoclave (Vitale, 12L, Cristófoli Equipamentos de Biossegurança Ltda, Campo Mourão, PR, Brazil).

Then, the toothbrushes were divided, randomly, into 5 brushing groups, with 3 toothbrushes in each group:

- group I (negative control): contamination of the toothbrush bristles and toothbrushing for $1 \mathrm{~min}$, without dentifrice;

- group II: contamination of the toothbrush bristles associated with toothbrushing for $1 \mathrm{~min}$, with fluoridated dentifrice (Sorriso, ColgatePalmolive Indústria e Comércio Ltda, São Bernardo do Campo, São Paulo, Brazil);

- group III: contamination of the toothbrush bristles associated with toothbrushing for $1 \mathrm{~min}$, with dentifrice containing triclosan associated with gantrez (Colgate total 12, Colgate-Palmolive Indústria e Comércio Ltda, São Bernardo do Campo, SP, Brazil);

- group IV (positive control): contamination of the toothbrush bristles associated with toothbrushing for $1 \mathrm{~min}$, without dentifrice, followed by irrigation with $10 \mathrm{~mL}$ of $0.12 \%$ chlorhexidine gluconate (Periogard, Colgate-Palmolive Indústria e Comércio Ltda);

- group V: contamination of the toothbrush bristles associated with toothbrushing for $1 \mathrm{~min}$, with dentifrice containing Aloe vera and propolis (Forever Bright with Aloe vera and bee propolis, Forever Living Products, Scottsdale, AZ, USA).

In each group, toothbrushing was performed on the flat enamel surface of a bovine tooth. In order to obtain this surface, 5 bovine premolars were cut $2.0 \mathrm{~cm}$ long by $1.0 \mathrm{~cm}$ wide under cooling using a high-speed dental drill with cylindrical diamond bur (KG Sorensen Indústria e Comércio Ltda, Barueri, $\mathrm{SP}, \mathrm{Brazil)}$. This size was compliant with the size of the toothbrush head used in the study (Figure 1a).

To make toothbrushing easier, the surface of the bovine tooth was fixed on an acrylic resin (JET, Artigos Odontológicos Clássico Ltda, Campo Limpo Paulista, SP, Brazil) block ( $2.5 \mathrm{~cm} \times 1.5 \mathrm{~cm} \times 1.0 \mathrm{~cm})$ The flat enamel surface was left a few millimeters above the level of the acrylic resin block, so that the toothbrush bristles had contact with this surface only during brushing. Then, the enamel surface/ acrylic resin block set was packed and sterile in an autoclave. For the brushing, 5 sets of the enamel surface/acrylic resin block were randomly divided for each brushing group (Figure 1b). 
The standard strain of S. mutans (ATCC 25175) was used for the contamination of the toothbrush bristles. Its culture was made in a test tube with $10 \mathrm{~mL}$ of $\mathrm{BHI}$ solution, incubated in an anaerobiosis jar under $37^{\circ} \mathrm{C}$ for 7 days. After the microbial growth, the samples were homogenized for $10 \mathrm{~s}$ in a tube shaker (Agitador de Tubos; AP56, Phoenix, Araraquara, SP, Brazil).

Then, 3 qualified researchers (A- MSC, B- PFRB and $C$ - SLP) performed the contamination of the bristle brush, the dentifrice distribution on the bristles, the toothbrushing and deposition of the bristles in the culture medium. The researchers were wearing sterile gloves, which were changed at the end of treatment of each group.

For the bristle contamination of each group, researcher $A$ opened the sterile packing, researcher $B$ took out the toothbrush and researcher $C$ spread $25 \mu \mathrm{L}$ of the standard strain with a micropipette on the first 3 rows of bristles away from the handle.

After the contamination, in groups II, III and V, the researcher $A$ distributed the dentifrices over the bristle area aided with the tip cut from its handle (Figure 2). Then, researcher $\mathrm{B}$ performed the brushing for $1 \mathrm{~min}$. In all groups, immediately after brushing, the researcher $B$ trimmed the first 3 rows of bristles of each toothbrush using a scalpel blade No. 12 (SurgiBlade, Sunshine Int'I, Miami, FL, USA), which was discarded at the ending of each group.

The trimmed bristles of each toothbrush were
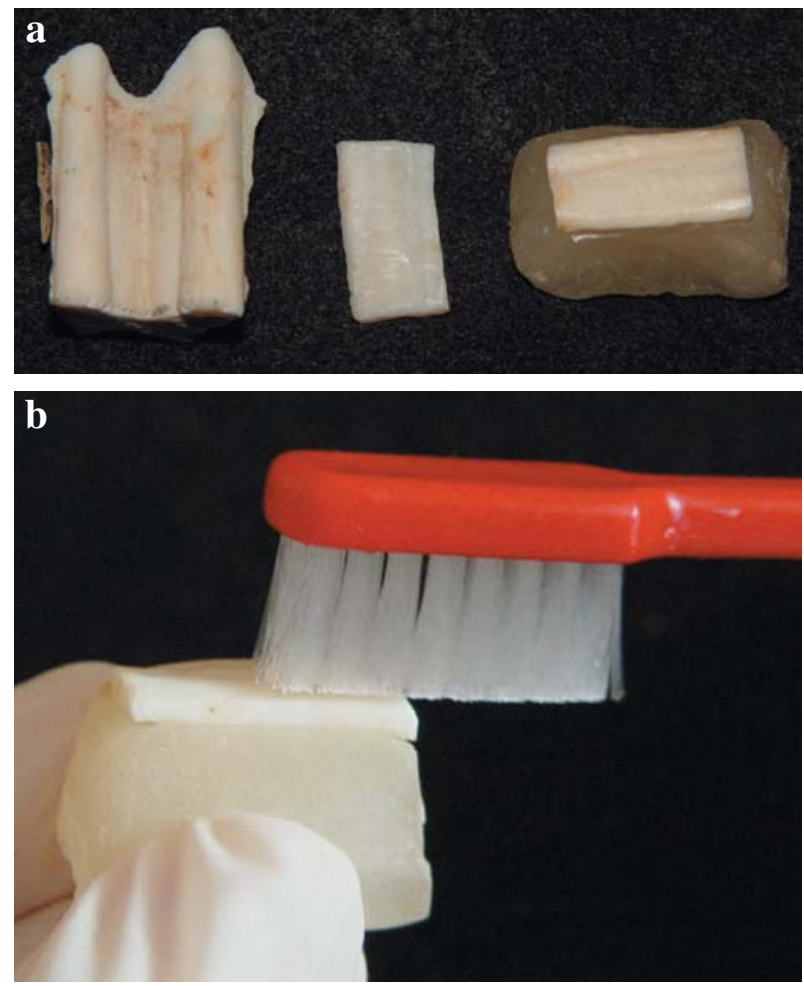

Figure 1- Bovine premolar tooth, and enamel surface fixed on an acrylic resin block (a) to facilitate the seizing for brushing (b) stored in an individually test tube with $3 \mathrm{~mL}$ of BHI solution, which were kept in anaerobiosis under $37^{\circ} \mathrm{C}$ for $48 \mathrm{~h}$. After, with a sterile swab the sowing was made in triplicate in the Mitis salivarius - Bacitracin medium. The samples were kept in anaerobiosis under $37^{\circ} \mathrm{C}$ for $48 \mathrm{~h}$.

To evaluate the results of each group, scores were used according to the number of colony forming units (cfu), as shown in Figure 3. Then, these data were submitted to the descriptive analysis and to the Mann-Whitney statistical test at $5 \%$ significance level.

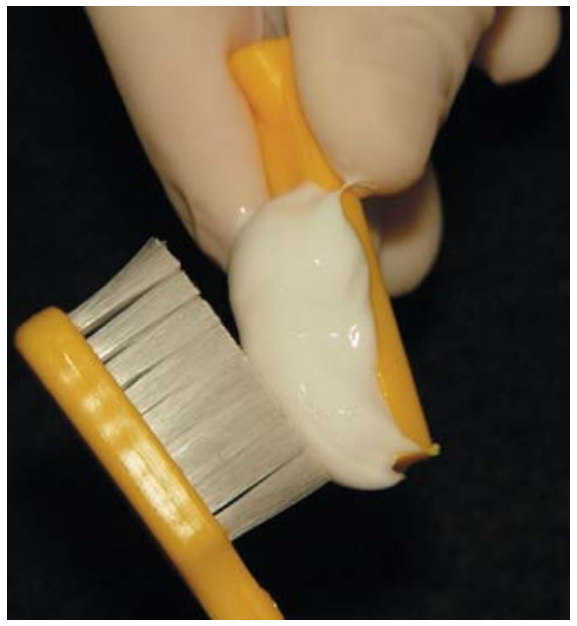

Figure 2- Cut tip handle to aid dentifrice placement onto the toothbrush bristles

\begin{tabular}{|c|c|}
\hline Score & $\mathbf{N}^{\circ}$. of colony forming units \\
\hline 0 & Absence of colonies \\
\hline 1 & 1 to 10 \\
\hline 2 & 11 to 1000 \\
\hline 3 & $>1000$ \\
\hline
\end{tabular}

Figure 3- Score used to count the colony forming units

Table 1- Score for colony forming units (cfu), descriptive analysis and Mann-Whitney statistical test

\begin{tabular}{llllll}
\hline Groups & Cfu score & & Average & $\begin{array}{l}\text { Standard } \\
\text { Deviation }\end{array}$ \\
\hline $\mathrm{la}$ & 3 & 3 & 3 & 3 & 0.0000 \\
$\mathrm{IIb}$ & 1 & 0 & 0 & 0.3333 & 0.5774 \\
$\mathrm{IIlb}$ & 1 & 1 & 0 & 0.6667 & 0.5774 \\
$\mathrm{IVb}$ & 0 & 0 & 0 & 0.0000 & 0.0000 \\
$\mathrm{Vb}$ & 1 & 0 & 0 & 0.3333 & 0.5774 \\
\hline
\end{tabular}

Roman numerals followed by different low case letters in the vertical, differ to each other statistically $(p<0.05)$. 


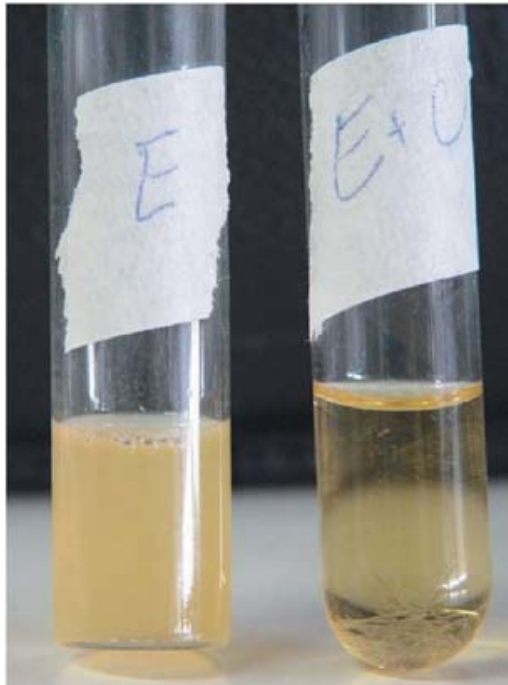

Figure 4- Results of bacterial growth in individual test tube. group I (E) and group IV $(E+U)$

\section{RESULTS}

The scores assigned to the cfu's counted for each group are shown in Table 1, where a statistically significant difference was found $(p<0.05)$ in the reduction of bristle contamination in groups II, III, IV and V compared to group I. However, there was no statistically significant difference among the groups that used the chemical agents to decontaminate the toothbrush bristles (Figure 4 and Figure 5).

\section{DISCUSSION}

After oral hygiene, the toothbrush bristles become contaminated by oral microorganisms. Oral health professionals must hence include instructions to post-hygiene care of the toothbrushes in order to reduce the contamination and, consequently, minimize the microbial transmission in the same

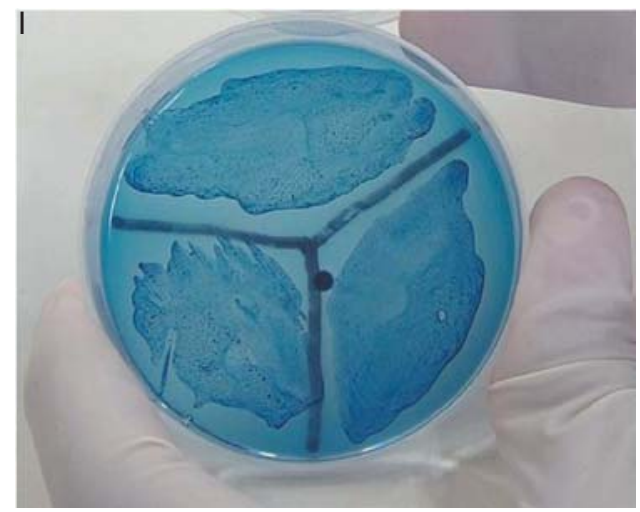

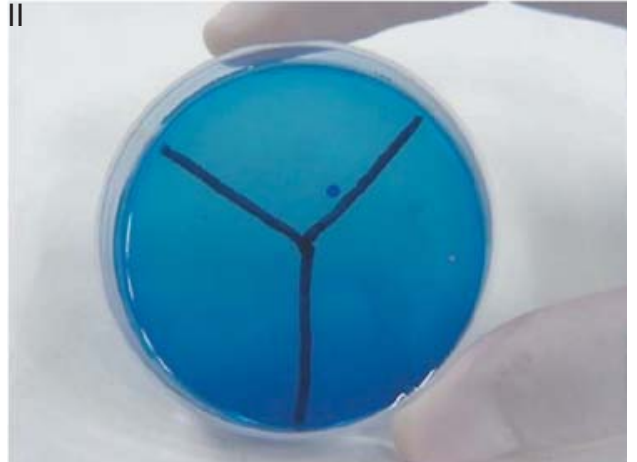

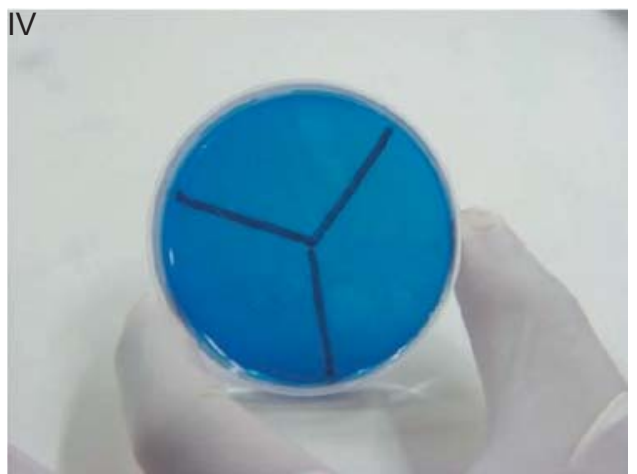

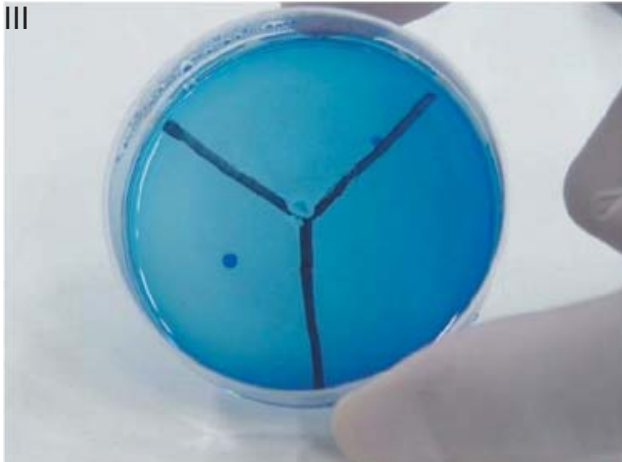

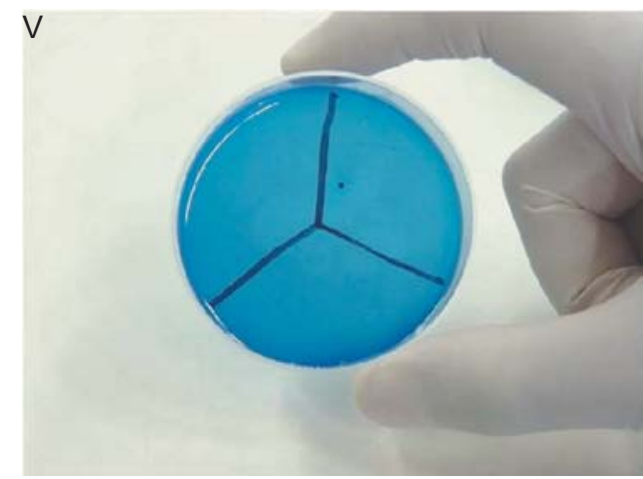

Figure 5- Characteristic of bacterial growth for group I, II, III, IV and V in the culture medium 
individual from one niche to another. According to Bhat, et al. ${ }^{3}$ (2005) and Nascimento, et al. ${ }^{17}$ (2008), the patient must be instructed to change toothbrush constantly and store it in a moisturefree environment in order to minimize the contamination.

Previous studies investigating bristle decontamination used different toothbrushing times. Warren, et al. ${ }^{25}$ (2001) established a toothbrushing time of $30 \mathrm{~s}$, while Nascimento, et al. ${ }^{17}$ (2008) established $2 \mathrm{~min}$. In this study, the toothbrushing time established for all groups was 1 min. According to the results presented by group I, this time was sufficient to contaminate the toothbrush bristles, and to perform the decontamination in all groups which used chemical agents.

Bunetel, et al. ${ }^{4}$ (2000) reported that the bristle and microorganism types affect toothbrush contamination. While, Carranza, et al. ${ }^{5}$ (2004) reported that toothbrushes with nylon bristles accumulated less microorganisms than the ones with natural bristles. In this study, the association of nylon bristles with the chemical agents used can be considered as a factor which contributed to the effective decontamination of the toothbrush bristles.

In some studies ${ }^{3,17}$, the head of the toothbrush was directly submerged in the test tube for the analysis of the decontamination of bristles. In this study, the bristles were trimmed and stored in individual test tubes, as previously suggested ${ }^{8,20}$.

Bacitracin antibiotic associated with the culture medium was used to inhibit the growth of other bacterial species and to promote only the selective growth of $S$. mutans strain, according to Nascimento, et al. ${ }^{17}$ (2008).

According to Beighton, et al. ${ }^{2}$ (1991), 0.12\% chlorhexidine gluconate presents essential characteristics due to its substantivity associated with the bactericidal activity at high concentrations. However, Emilson and Lindquist ${ }^{9}$ (1988) reported the incapacity of chlorhexidine to eliminate permanently $S$. mutans from the tooth surfaces.

After toothbrushing without dentifrice in the group IV of this study, the decontamination of the toothbrush bristles was performed by irrigation with $0.12 \%$ chlorhexidine gluconate. The culture obtained from these bristles did not promote the bacterial growth, and this method was proven effective for the decontamination of toothbrush bristles for the strain used. The same finding has been reported by Nascimento, et al. ${ }^{17}$ (2008) in an in vivo study involving $S$. mutans, where the toothbrush bristles were decontaminated using $0.12 \%$ chlorhexidine gluconate spray.

In the present study, the form of dentifrice distribution on the toothbrush bristles may have increased its contact with the microorganisms and, consequently, promoted its action for the decontamination of the bristles.

In groups II and III, both dentifrices were fluoridated, with a concentration of $1450 \mathrm{ppm}$, complying with ANVISA requirements. Although there was no significant difference between the scores presented for cfu, the dentifrice from group II presented some scores lower than the ones obtained for the dentifrice from group III. However, the dentifrice used in group $V$ does not contain fluoride in its formulation, and contains Aloe vera associated with propolis. According to Lee, et al. ${ }^{16}$ (2004), Aloe vera's has anti-inflammatory, immunestimulating, analgesic and antimicrobial activities against oral microorganisms, among which $S$. mutans.

The antimicrobial action of propolis is associated with its capacity of inhibiting the glucosyltransferase activity, which is essential for $S$. mutans to catalyze the formation of soluble and insoluble glycans, as well as to provide adherence ${ }^{14,16}$. Some authors have reported that triclosan is not so effective to inhibit it ${ }^{14,15,24}$.

According to the results of an in an in vitro study ${ }^{1}$, the dentifrice containing triclosan presented a significant antimicrobial action against standard strain of $S$. mutans when compared to the dentifrice containing Aloe vera associated with propolis. In this study, there was no difference among the dentifrices used for bristle decontamination.

The significant reduction of the toothbrush bristle contamination is dependent on the dentifrice formulation ${ }^{20}$. The results observed in the current study did not show significant difference in the reduction of bristle contamination among the different dentifrices used in the groups. This could be associated with the presence of detergents in their formulas, which is reported to aid the reduction of survival of pathogenic species ${ }^{21}$. In this study, the efficiency of dentifrice to reduce the contamination of the toothbrush bristles may have also been supported by the action of the sodium lauryl sulfate detergent, which is present in all dentifrices used.

As there is no reported study using Aloe vera associated with propolis dentifrice to decontaminate the toothbrush bristles, further in vitro and in vivo studies involving different bacterial types must be performed to support its efficacy.

\section{CONCLUSION}

Within the limits of this study, it may be concluded that all the chemical agents used were effective to reduce the contamination by the standard S. mutans strain on toothbrush bristles. The dentifrice containing Aloe vera and propolis reduced the contamination of toothbrush bristles, though without differing significantly from the other 
groups that used chemical agents.

\section{REFERENCES}

1- Barreto VL, Feitosa AMSCA, Araújo TJ, Chagas FK, Costa LK. Acción antimicrobiana in vitro de dentífricios conteniendo fitoterápicos. Av Odontoestomatol. 2005;21:195-201.

2- Beighton D, Decker J, Jomer KA. Effects of chlorhexidine on proteolytic and glycosidic enzyme activities of dental plaque bacteria. J Clin Periodontol. 1991;18:85-9.

3- Bhat SS, Hegde KS, George RM. Microbial contamination of tooth brushes and their decontamination. J Indian Soc Pedod Prev Dent. 2003;21:108-12.

4- Bunetel L, Tricot-Doleux S, Agnani G, Bonnaure-Mallet M. In vitro evaluation of the retention of three species of pathogenic microorganism by three different types of toothbrush. Oral Microbiol Immunol. 2000;15:313-6.

5- Carranza FA, Newman MG, Takei HH. Carranza's clinical periodontology. Philadelphia: W.B. Saunders; 2002.

6- Cobb CM. Toothbrushes as a cause of repeated infections of the mouth. Boston Med Surg J. 1920;183:263-4.

7- Rezende GPSR, Pimenta FC, Costa LRRS. Antimicrobial activity of two Brazilian commercial propolis extracts. Braz J Oral Sci. 2006;5:967-70.

8- Efstratiou M, Papaioannou W, Nakou M, Ktenas E, Vrotsos IA Panis V. Contamination of a toothbrush with antibacterial properties by oral microorganisms. J Dent. 2007;35:331-7.

9- Emilson CG, Lindquist B. Importance of infection level of mutans streptococci for recolonization of teeth after chlorhexidine treatment. Oral Microbiol Immunol. 1988;3:64-7.

10- Goldschmidt MC, Warren DP, Keene HJ, Tate WH, Gowda C. Effects of an antimicrobial additive to toothbrushes on residual periodontal pathogens. J Clin Dent. 2004;15:66-70.

11- Gomes RT, Teixeira KIR, Cortés ME, Santos VR. Antimicrobia activity of a propolis adhesive formulation on different ora pathogens. Braz J Oral Sci. 2007;6:1387-91.

12- Jones CL, Ritchie JA, Marsh PD, van der Ouderaa F. The effect of long-term use of a dentifrice containing zinc citrate and a nonionic agent on the oral flora. J Dent Res. 1988;67:46-50.

13- Komiyama EY, Back-Brito GN, Balducci I, Koga-Ito CY. Evaluation of alternative methods for the disinfection of toothbrushes. Braz Oral Res. 2010;24:28-33.
14- Koo H, Cury JA, Rosalen PL, Ambrosano GMB, Ikegaki M, Park YK. Effect of a mouthrinse containing selected propolis on 3-day dental plaque accumulation and polysaccharide formation. Caries Res. 2002;36:445-8.

15- Koo H, Vacca Smith AM, Bowen WH, Rosalen PL, Cury JA, Park YK. Effects of Apis mellifera propolis on the activities of streptococcal glucosyltransferases in solution and adsorbed onto saliva-coated hydroxyapatite. Caries Res. 2000;34:418-26.

16- Lee SS, Zhang W, Li Y. The antimicrobial potential of 14 natural herbal dentifrices: results of an in vitro diffusion method study. J Am Dent Assoc. 2004;135:1133-41.

17- Nascimento AP, Faria G, Watanabe E, Ito IY. Efficacy of mouthrinse spray in inhibiting cariogenic biofilm formation on toothbrush bristles. Braz J Oral Sci. 2008;7:1489-92.

18- Offenbacher S, Olsvik B, Tonder A. The similarity of periodontal microorganisms between husband and wife cohabitants. Association or transmission? J Periodontol. 1985;56:317-23.

19- Preus HR, Zambom JJ, Dunford RG, Genco RJ. The distribution and transmission of Actinobacillus actinomycetemcomitans in families with established adult periodontitis. J Periodontol. 1994;65:2-7.

20- Quirynen M, De Soete M, Pauwels M, Gizani S, van Meerbeek $B$, van Steenberghe $D$. Can toothpaste or a toothbrush with antibacterial tufts prevent toothbrush contamination? J Periodontol. 2003;74:312-22

21- Quirynen M, De Soete M, Pauwels M, Goossens K, Teughels W, van Eldere J, et al. Bacterial survival rate on tooth- and interdenta brushes in relation to the use of toothpaste. J Clin Periodontol. 2001;28:1106-14

22- Reynolds T, Dweck AC. Aloe vera leaf gel: a review update. J Ethnopharmacol. 1999:68:3-37.

23- Sato $S$, Ito IY, Lara EHG, Panzeri $H$, Albuquerque Júnior RF Pedrazzi V. Bacterial survival rate on toothbrushes and their decontamination with antimicrobial solutions. J Appl Oral Sci. 2004; 12:99-103.

24- Schiling KM, Bowen WH. Glucans synthesized in situ in experimental salivary pellicle function as specific binding sites for Streptococcus mutans. Infect Immun. 1992;60:284-95. 25- Warren DP, Goldschmidt MC, Thompson MB, Adler-Storthz $\mathrm{K}$, Keene $\mathrm{HJ}$. The effects of toothpastes on the residual microbial contamination of toothbrushes. J Am Dent Assoc. 2001;132:1241- 